pite a widespread if still incomplete familiarity with contraceptive techniques suggest that a much more thorough attack on the problem is needed. The total of 86,565 operations in England and Wales in $1970^{1}$ is already dwarfed by the provisional figure for 1971 of 126,734 . And of nearly 76,000 cases in 1970 in which the occupation of the woman is stated $40,759(54 \%)$ were in the professional and skilled classes, a much larger proportion than in the general population.

Another report issued last week looked at the cost to the community of "unwanted" children, ${ }^{2}$ and had no difficulty in showing from a variety of ingenious estimates that it is very much higher than the cost of preventing unwanted children. If this encourages local authorities to put some drive into the facilities for family planning that they are or ought to be providing it will serve a useful purpose. The success of a domiciliary service at reasonable cost has recently been described. ${ }^{3}$ But one difficulty is that human nature is more wayward than planners are apt to think. A child may be unwanted when born but become a loved member of the family, or be wanted when born and rejected later, or wanted by one parent and not by the other, or evoke conflicting responses at different levels of its mother's or father's mind. These familiar vagaries of parenthood no doubt provide another set of reasons besides the passion of a moment why the availability of contraception is not the whole answer to the problem of unwanted children.

If doctors have an obligation to speak out on the "British disease of overpopulation" 4 they have a duty likewise to be far more concerned with family planning than they have been. As a profession we must admit to being slow in recognizing the needs of our patients for advice and treatment. Has the subject yet achieved the place it ought to hold in medical education? Are patients everywhere receiving the guidance they want but sometimes scarcely know how to ask for? Family planning must be accepted as one of the essential public health measures of our day.

\footnotetext{
1 Tho Registrar General's Statistical Review of England and Wa'es for the year 1970-Supplement on Abortion. London, H.M.S.O., for the
1972 .
aing,

Laing, W. A.. The Costs and Benefits of Family Planning, PEP Broadsheet 534, February 1972, 60p.

3 Wilson, E., British Medical fournal, 1971, 4, 731.

+ Anderson, J. A. D., et al., British Medical fournal, 1972, 1, 108.
}

\section{Studies on Orgasm}

Improved surgical and electroencephalographic techniques have now made it feasible to study patients with intractable epilepsy by implanting electroencephalographic electrodes on the surface and deep in the brain. In some patients with epilepsy these investigations undoubtedly have a valuable role in the assessment of their disease. Nevertheless, many doctors will wish to think carefully about the issues raised by a recent report of two such studies. ${ }^{1}$

The first of these investigations was carried out in 1960 and 1961 on a 34-year-old woman described as "of borderline defective intelligence." She had a long history of severe petit mal, psychomotor, and grand mal epilepsy which had been poorly controlled with a range of anticonvulsant drugs. The second study, done in 1970, was carried out on a 24 year-old man in whom two main diagnoses had been made: personality disorder with homosexual behaviour and drug experimentation, and electroencephalographic evidence of temporal lobe dysfunction.

Under general anaesthesia both patients had electrodes implanted stereotactically into various sites deep in the brain and on the cortical surface; cannulas were implanted into the septal region and the hippocampus. Though both devices were used in treatment, the report deals mainly with their use in a study of patients' responses to stimulation of some areas of the brain. In the woman injections through the cannulas of minute amounts of acetylcholine (on 12 occasions) and noradrenaline (on four) into the septal region resulted in mild euphoria and sexual arousal, usually culminating in repetitive orgasms. During the four months the injections were given this patient did not have an epileptic seizure.

In the male patient the responses to electrical stimulation of the brain were studied. In part of this investigation a self-stimulating transistorized device was used, designed originally for demonstrating "the pleasure response in animals." The man was allowed to wear the device for three hours at a time, and, though he explored the effects of stimulating various areas of the brain, he chose to stimulate the septal area repeatedly-up to 1,500 times on one occasion. This stimulation was accompanied by feelings of pleasure, alertness, goodwill, and sexual arousal.

The report deals with attempts to alter the patient's sexual orientation by electrical stimulation of the "brain's pleasure sites." Before stimulation had begun his interests had been entirely homosexual. But during the phase of self-stimulation he showed increasing heterosexual interests, and was sexually aroused when he was shown a "stag" film which displayed heterosexual foreplay and intercourse. After another seven days of use of the self-stimulation unit he achieved successful intercourse with a 21-year-old prostitute, who had agreed to spend time with him in a specially prepared laboratory. As in the woman patient, the brain responses to these events were monitored electroencephalographically.

Though the article does not record it, one must presume that fully informed consent was obtained from both patients for all these procedures. And one must also presume that they were done wholly for the patients' benefit (in the case of the man details of treatment and its results are to be the subject of another report). Yet, even presuming these conditions were fulfilled, many doctors will be disturbed by this report, and wonder whether it does not challenge the whole concept of the dignity of man.

1 Heath, R. G., fournal of Nervous and Mental Disease, 1972, $154,3$.

\section{Interstitial Cystitis}

Recently A. W. Badenoch ${ }^{1}$ drew attention to the relatively uncommon but extremely troublesome condition of interstitial cystitis, first described by G. L. Hunner ${ }^{2}$ in 1914. In fact, the name "Hunner's ulcer" is still commonly used, but it is clearly a misnomer as pathological examination invariably shows a dense, diffuse fibrosis of the bladder wall, particularly invading the muscular layers. The condition is probably not primarily inflammatory, and $\mathbf{M}$. R. Silk ${ }^{3}$ has suggested that it is an autoimmune disease and is associated with an abnormality affecting collagen. This view has been supported by G. M. Fister, ${ }^{4}$ who compared the condition 